Enhancing student learning experience with technology-mediated gamification: An empirical study

Crystal Han-Huei Tsay ${ }^{\mathrm{a},}$, Alexander Kofinas ${ }^{\mathrm{b}}$, Jing Luo $^{\mathrm{a}}$

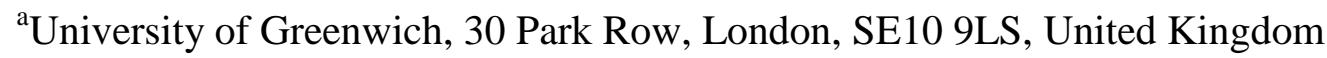

${ }^{\mathrm{b}}$ University of Bedfordshire, University Square, Luton LU1 3JU, United Kingdom

*Corresponding author: Crystal Han-Huei Tsay, Department of Human Resources

and Organisational Behaviour, University of Greenwich, 30 Park Row, London, SE10

9LS, United Kingdom. Email: th23@gre.ac.uk; crystal.h.tsay@ gmail.com.

Emails:

Crystal Han-Huei Tsay: th23@gre.ac.uk

Alexander Kofinas: Alexander.Kofinas@ beds.ac.uk

Jing Luo: J.Luo@greenwich.ac.uk 


\title{
Enhancing student learning experience with technology-mediated gamification: An
} empirical study

\begin{abstract}
We evaluated the use of gamification to facilitate a student-centered learning environment within an undergraduate Year 2 Personal and Professional Development (PPD) course. In addition to face-to-face classroom practices, an information technology-based gamified system with a range of online learning activities was presented to students as support material. The implementation of the gamified course lasted two academic terms. The subsequent evaluation from a cohort of 136 students indicated that student performance was significantly higher among those who participated in the gamified system than in those who engaged with the nongamified, traditional delivery, while behavioral engagement in online learning activities was positively related to course performance, after controlling for gender, attendance, and Year 1 PPD performance. Two interesting phenomena appeared when we examined the influence of student background: female students participated significantly more in online learning activities than male students, and students with jobs engaged significantly more in online learning activities than students without jobs. The gamified course design advocated in this work may have significant implications for educators who wish to develop engaging technology-mediated learning environments that enhance students' learning, or for a broader base of professionals who wish to engage a population of potential users, such as managers engaging employees or marketers engaging customers.
\end{abstract}

Keywords: Gamification, higher education, student engagement, flipped classroom, studentcentered learning 


\section{Introduction}

In recent decades, the policies and practice of the widening participation initiative have led to an increasingly diverse and heterogeneous student body in higher education, challenging how things are done within the sector. Engaging students in learning is becoming a priority for many educators (Gibbs, 2014) and has generated a number of approaches: student-centered learning (Baeten, Kyndt, Struyven, \& Dochy, 2010; Hannafin \& Land, 1997; Lea, Stephenson, \& Troy, 2003), flipped classroom (Gilboy, Heinerichs, \& Pazzaglia, 2015; McLaughlin et al., 2014), and technology-mediated learning (Chen, Lambert, \& Guidry, 2010; Hepplestone, Holden, Irwin, Parkin, \& Thorpe, 2011; Price \& Kirkwood, 2011). While these approaches seem focused on improving teaching and learning, a critical question is how to implement these approaches successfully, as they seem to contradict the current drive within higher education for standardization (Wood \& Reiners, 2012). Educational gamification, i.e., the application of game mechanics and elements in an educational context, often with the support of a virtual learning environment (VLE), may be a means of offering a user-centered, autonomous, and flexible learning environment, which can encourage users to pursue their own goals (Landers \& Callan, 2011) and engage in deeper-level activities more persistently (A. Anderson, Huttenlocher, Kleinberg, \& Leskovec, 2014). An information technology (IT)-based gamified course design necessitates the adoption of the motivational properties of games into teaching and learning, thus taking into account the human desire to communicate and share accomplishments as a means of motivating students to learn (Landers \& Callan, 2011; Nicholson, 2012). If successful, such an approach could potentially result in a longterm and deeper engagement among learners (Nicholson, 2012).

Empirical studies have presented efforts of IT-based gamification in the context of higher education with positive-leaning but mixed results (Dicheva, Dichev, Agre, \& Angelova, 2015; Seaborn \& Fels, 2015). Researchers have speculated that these mixed results 
may be due to contextual factors such as the design of the gamified system, player qualities, overall goals, interests, and needs (Hamari \& Koivisto, 2015; Hamari, Koivisto, \& Sarsa, 2014). Despite agreement among educators that a learning environment cannot operate in a vacuum (Slavin, 1987) and that student background influences the learning process and outcomes (Baeten, Kyndt, Struyven, \& Dochy, 2010; Lim \& Kim, 2003), very few studies have explicitly recognized and examined the background elements that students bring to a gamified course. Such variables, if not attended to, could make the system inappropriate for the players it was designed to support. It was our goal to fill these gaps in the literature. Thus, two focal research questions (RQs) were addressed in this study:

RQ1. To what extent can an IT-based gamified system within a course enhance student learning?

RQ2. Which background factors may influence students' engagement in such a gamified course?

We begin by introducing the concept and theoretical foundations of gamification, examining the link between a gamified course, student performance, and the learning experience. A number of background variables have been identified from the literature, and their significance in the effectiveness of a gamified course is evaluated. Following the presentation of the study's methods and results, the discussion focuses on how a gamified course design can sustain meaningful teaching and learning. A further contribution is made for meaningful gamification by identifying outcome indicators and involving the students (endusers) in each stage of the course design process. 


\section{Theoretical background}

\subsection{Gamification and motivation}

Gamification can be defined as "the use of game design elements and game thinking in non-game contexts" (Deterding, Dixon, Khaled, \& Nacke, 2011). This term was first used in 2008 but was not widely adopted until 2010; now it is seen as an instance when a system designer takes the motivational properties of games and applies them in other learning activities, while taking into account the human desire to communicate and share accomplishments through goal setting to direct the attention of learners and motivate them (Landers \& Callan, 2011). Gamification is regarded as the cutting edge in marketing and customer engagement from companies and commentators (Zichermann \& Cunningham, 2011), mainly because it generates positive, intrinsically motivating, and "gameful" experiences (Huotari \& Hamari, 2012; Ryan \& Deci, 2000). It is precisely this aspect of engagement that makes gamification relevant to the higher education context, and it has been seen as a potential solution for student engagement (de Sousa Borges, Durelli, Reis, \& Isotani, 2014; Dicheva, Dichev, Agre, \& Angelova, 2015). Furthermore, a gamified system that puts users in the heart of the design can facilitate development of a learner-centered learning environment and lead to desirable outcomes such as wider participation, long-term engagement, and academic success (Lonka \& Ahola, 1995).

At the heart of gamification is motivation. Self-determination theory, an influential motivation theory proposed by (Deci \& Ryan, 2002), provides a significant theoretical foundation for gamification, as it focuses on the degree to which an individual's behavior is self-motivated and self-determined. A gamified system should eventually aim to provide users a sense of autonomy, competence, and/or (social) relatedness, because these elements ultimately intrinsically sustain and motivate people. While self-determination theory focuses on what drives an individual to make choices without external influences, the organismic 
integration theory has attempted to extend the theory by exploring how different types of external motivation can be embedded into the activity at hand and eventually lead into someone's sense of self (Baard, Deci, \& Ryan, 2004). Organismic integration theory argues that rewards based on gaining or losing status and tapping into the ego of the participants create an introjected regulation of behavior. However, the controlling aspects of the reward mechanisms may cause the loss of intrinsic motivation, i.e., all forms of rewards based on extrinsic motivation will eventually erode intrinsic motivation (Deci, Koestner, \& Ryan, 2001). Hence, Nicholson (2012) suggested that designers should involve the users to enable customization of the gamified system and select meaningful game elements and goals that fall in line with users' own interests to sustain their intrinsic motivation. Thus, learners would eventually engage with activities that are intrinsically meaningful and rewarding.

Researchers concerned with how to intrinsically motivate users in gamified systems that are built on self-determination theory and organismic integration theory principles may utilize concepts such as situated motivational affordance (Deterding, Dixon, Khaled, \& Nacke, 2011) and user-centered design (Nicholson, 2012; Norman, 1990). Deterding et al. (2011) proposed a related theory out of human-computer interaction studies called situated motivational affordance, i.e., the idea that IT designers should consider the context of each element of a system. Thus, a user would be motivated by an aspect of the IT system only when there is a match between that aspect and the background of the user.

Research on educational gamification suggests that a variety of game components may provide motivational affordance to student users (Dicheva, Dichev, Agre, \& Angelova, 2015). They consist of a wide range of design principles (such as goals, competition and cooperation, freedom to fail, and many others) and game mechanics (e.g., avatars, badges, boss fights, content unlocking, and others), which when combined can motivate users to engage in learning activities (Iosup \& Epema, 2014; Landers \& Callan, 2011). While some 
game components, such as badges, points, levels, and virtual goods, can act as external rewards, other game components, such as social graphs, teams, and content unlocking, can serve as intrinsic motivators to students who imbue these components with personally important meanings (Banfield \& Wilkerson, 2014).

User-centered design is a framework of processes in which system designers give extensive attention to the needs, wants, and limitations of end users of a system throughout the system life cycle (Gulliksen et al., 2003; Norman, 1990). The higher education context has a range of learners, and a gamified course must consider in its design these users' diverse needs and interests (de-Marcos, Garcia-Lopez, \& Garcia-Cabot, 2016). Gulliksen et al. (2003) suggested 12 user-centered design principles, among which a user-centered attitude, user focus (e.g., understanding users' goals, tasks, and needs, the goals of user activities, and the context of use), active user involvement (in the entire development process), and evaluation of use-in-context are closely aligned with a pedagogical approach of student-centered learning. This approach mandates emphasis on student responsibility and activity in learning and the consultation of students about the learning and teaching process. A teacher is considered to be a "guide on the side," assisting students to meet learning goals that have been co-created by the students and the teacher (Baeten, Kyndt, Struyven, \& Dochy, 2010; Hannafin \& Land, 1997; Lea, Stephenson, \& Troy, 2003). Research evidence has shown that the student-centered learning approach increases student participation, motivation, and longterm academic success (Lonka \& Ahola, 1995).

Both user-centered design and student-centered learning focus on understanding user/learner needs as part of determining the system's effectiveness. Furthermore, both approaches aim to achieve a similar learning environment by providing faster feedback and more flexibility for the learner (Caton \& Greenhill, 2013), opportunities to compare a learner's progress with others, co-creation of knowledge in community and expression of 
individuality (Nicholson, 2015; Wood \& Reiners, 2012)), higher student satisfaction (Barata, Gama, Jorge, \& Gonçalves, 2013; Cruz \& Penley, 2014), and intrinsic motivation for students to take on challenging learning tasks (Banfield \& Wilkerson, 2014; Cruz \& Penley, 2014; Hamari \& Koivisto, 2015; Iosup \& Epema, 2014; Wood \& Reiners, 2012). We argue that the successful integration of design principles and student -centered learning within a gamification system will increase student participation, motivation, and performance. Therefore, two hypotheses are proposed:

H1: Students' engagement in the gamified course is positively related to their course performance.

H2: Students' course performance is higher in the gamified course than in the nongamified course.

\subsection{Contextual influences}

A substantial body of empirical studies has reported mixed or even negative results from gamification interventions (Seaborn \& Fels, 2015). For example, Domínguez et al. (2013) found that students exposed to a gamified experience had better scores in practical assignments and in the overall score, but performed poorly on written assignments and participated less in class activities (Domínguez et al., 2013). In other studies, gamification did not seem to have a significant impact, as it created cognitive dissonance (education as work opposed to education as fun) (Denny, 2013; Gåsland, 2011; Hanus \& Fox, 2015). Hanus and Fox (2015) compared a range of learning outcomes between students who participated in a gamified course (featuring a leaderboard and badges) and those who did not and found that students in the gamified course showed less intrinsic motivation, satisfaction, and empowerment over time than those in the nongamified class. Furthermore, the former group of students had lower performance on the final exam. 
do not enter a learning environment like 'empty vessels' but bring their own experience with them; such background factors influence their perception of and participation in a gamified course. This argument is echoed by gamification research that shows that user qualities often have an impact on attitudes towards gamification (Antin, 2012; Cruz \& Penley, 2014; Hamari \& Tuunanen, 2014; Hanus \& Fox, 2015; Koivisto \& Hamari, 2014). For example, Landers and Armstrong (2015) applied technology-mediated gamification in a training session and found that users' prior experience and attitudes towards game-based learning also influenced their motivation (i.e., valence) in participating in a gamified system. Their results showed that while participants with positive attitudes toward game-based learning had greater valence for gamified instruction compared to traditional lecture-andPowerPoint-based training, participants with poor attitudes toward game-based learning and limited experience with video games had weaker valence for gamified instruction.

A gap that remains in the literature is the lack of systematic examinations of "what" user background variables to include and "how" they influence a gamified system. We therefore identified a number of student background variables based on the marketing literature and the online learning literature as an exploratory approach to understand the impact of user background characteristics in a gamified system. In the marketing literature, users are categorized based on geographic (e.g., country, county, city), demographic (e.g., age, gender, education, social status), and psychographic (e.g., attributes, interests, values, lifestyle) differences (Hamari \& Tuunanen, 2014). Similarly, in the online learning literature, researchers examine variables related to student characteristics, such as demographic factors, motivational factors, and factors related to general cognitive ability (Lim \& Kim, 2003). Due to the exploratory context and sample characteristics of this research project, the demographic and psychographic variables that were examined were gender, motivation, and job status. 
limited interest in a learning task or memorization and reproduction of elements that seem appropriate. Deep learning, on the other hand, is associated with attempts to understand a topic if it is of real interest to them or if they can see its relevance to their current or future professional roles (Kember, Charlesworth, Davies, McKay, \& Stott, 1997). Deep learning is associated with an intrinsic orientation in motivation (Deci \& Ryan, 2002), motivation to study, and a range of mastery-approach goals (Baeten, Kyndt, Struyven, \& Dochy, 2010). In contrast, surface learning is associated with an extrinsic orientation in motivation, fear of failure, and performance avoidance goals (Baeten, Kyndt, Struyven, \& Dochy, 2010). Thus, in a gamified course where there are optional learning activities, students with a surface learning orientation will be less likely to participate in the gamified activities. However, game mechanics that generate positive, intrinsically motivating experiences would tap into intrinsic motivation, so naturally learners with a deep approach would be more engaged. We therefore hypothesized:

H4a: A deep study approach is positively related to behavioral engagement in a gamified course.

H4b: A surface study approach is not significantly related to behavioral engagement in a gamified course.

Another student background factor that is worthy of examination is job status, as nearly two -thirds of UK students are now working part -time during the term to help fund their studies and accommodation and living costs, as well as prepare themselves for the job market (Richmond, 2013). Thus, students need to juggle multiple life demands such as job and family responsibilities in addition to their academic workload. If demands from a part time job make it difficult for an individual to fulfill the requirements of the student role, he or she may experience time-based conflicts and spend less time in academic activities (Greenhaus \& Beutell, 1985). Indeed, research has shown that the adverse effects of part - 
time work on study take the form of missed lectures, and students perceive coursework grades to be lower than they would have been had they not been working (Hall, 2010). In the context of this gamified course, we therefore hypothesize:

H5: Students with part-time jobs engage less in the gamified course.

\section{Methodology}

\subsection{Context of the study}

The course chosen for the gamified intervention is titled Personal and Professional Development (PPD) 2: Business Communication and Research. This is one of three PPD courses offered to undergraduate students in the business school of a post-1992 university in the UK designed to help students' employability (Yorke \& Knight, 2006). Topics covered include values and transferable skills, critical thinking, and other such practical skills (e.g., research skills on conducting small -scale management research). In the past, the course was delivered in a traditional manner with lectures and seminars taking place in alternate weeks for two terms (Week 1 to 12 in Term 1 and Week 13 to 24 in Term 2). The teaching team consisted of the course leader and 12 personal tutors, with each tutor responsible for 12 to 16 students. Lecture materials were delivered by the course leader using PowerPoint slides in a large lecture hall; seminar activities were led by personal tutors to reinforce students' learning of lecture materials. There were well-documented issues with this course: mainly low student engagement and complaints regarding limited contact hours.

The solution adopted was to develop a student-centered learning environment (Hannafin \& Land, 1997) in the form of an IT-based gamified intervention. In the academic year 2015-16, the structure was changed to weekly seminars, and learning activities were designed in a way that students actively participated in discussions and exercises and tutors acted as facilitators. Furthermore, the online learning activities were developed with the support of the institution's VLE (i.e., Moodle) and were classified in a two-tiered system with 
14 Essential Learning (EL) and 37 Super Learning (SL) activities. (See Appendices A and B improvement of the course and activity design. Informal face-to-face feedback regarding incentive mechanisms was also sought from students.

To tap into motivational affordance (Deterding, Dixon, Khaled, \& Nacke, 2011), EL and SL activities were aligned with the course's learning objectives and were presented to students as challenges within a competitive framework. EL activities introduced to students content covered in the course, in the form of short texts, quizzes, and video clips from the public domain. Moodle bestows on the students a freedom to fail; that is, they can retake EL activities and quizzes. The rapid feedback mechanism was provided with simple texts after completing an EL task, such as "Thank you for participating in Essential Learning" or "Well done!" Students also received correct answers from quizzes immediately after activity completion. Students were required to complete weekly or biweekly EL activities before attending seminar class, and their participation was a major part of their Engagement score (10\% of the final total mark).

SL was framed as optional online learning activities that would help students learn "above and beyond" what was essential and would enhance the quality of the two summative assignments. Applying self-determination theory (Deci \& Ryan, 2002) and organismic integration theory (Baard, Deci, \& Ryan, 2004) in activity design, SL activities pertained to 
different levels of difficulty following Bloom's taxonomy (L. W. Anderson, Krathwohl, \& Bloom, 2001). Also, most SL activities were not timebound (see Appendix B). Students thus had freedom to choose what SL activities to participate in and when and where to participate in them, which gave the users a sense of autonomy (Deci \& Ryan, 2002). The 11 time-bound activities were restricted only for feedback -type tasks and activities that required students to submit evidence from their classroom learning. To give students a sense of competence (Deci \& Ryan, 2002), badges and leaderboards were used to reward them for achievement. Figure 1 shows the EL badge and three SL badges (bronze, silver, and gold), which were awarded for completion of tasks. Gold badges were designed for higher-level learning tasks involving evaluation and analysis; silver badges were designed for intermediate -level tasks associated with feedback and application; and bronze badges were developed for comprehension and understanding types of tasks (L. W. Anderson, Krathwohl, \& Bloom, 2001). In addition, leaderboards were used to inform students of their progress in relation to their peers. Figure 2 shows a leaderboard example. The first leaderboard was announced at the end of week 3 , the second at the end of week 8 , the third at the end of week 18 , and the final one at the end of term 2 (week 24).

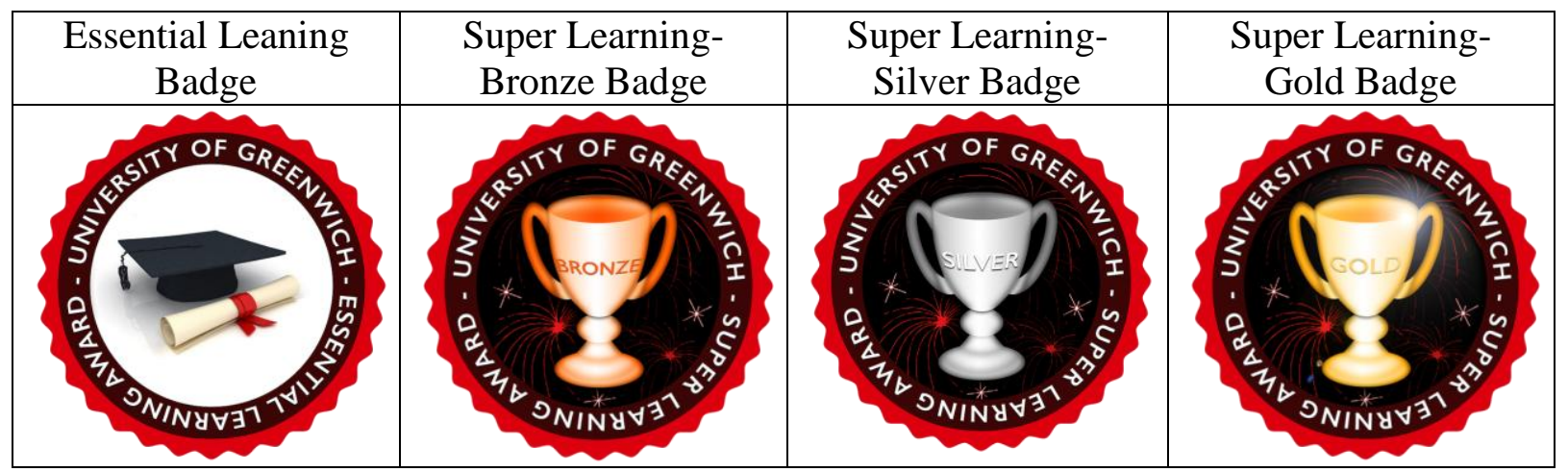

Fig 1. Essential Learning and Super Learning badges. 
This leader board result is based on students' activity completion from 26th September to 23rd October. Among students in PPD2, ' students have participated at least $1 \mathrm{SL}$ activity. The SL activities are categorised into three levels of difficulty based on Bloom's taxonomy and then depending on the level of difficulty, different points are allocated to the activity.

This table shows points associated with each SL. Top 12 Super Learners were then identified based on calculation of points achieved.

\begin{tabular}{|c|c|c|}
\hline Rank & Super Learner & pts \\
\hline 1 & & 420 \\
\hline 1 & & 420 \\
\hline 3 & & 410 \\
\hline 4 & & 380 \\
\hline 5 & & 370 \\
\hline 6 & & 360 \\
\hline 7 & & 330 \\
\hline 7 & & 330 \\
\hline 9 & & 320 \\
\hline 9 & & 320 \\
\hline 9 & & 320 \\
\hline 9 & & \\
\hline
\end{tabular}

Fig 2. Super Learning Leaderboard

To give students a sense of relatedness (Deci \& Ryan, 2002) and social engagement, tasks were designed to allow students to co-create knowledge and express individuality (Wood \& Reiners, 2012). As one example, discussion questions were posted using Moodle Forum. When students posted answers on a forum, they could see and rate other people's posts. As another example, students were invited to edit their user profiles, introducing themselves and talking about personal experiences. Furthermore, the course leader regularly monitored students' posts on the forum and provided feedback.

A total of 166 students were enrolled in the course. We informed students that the student information sheet and data on Moodle would be used for course improvement. With an option for students to opt out, 136 students completed it, resulting in a response rate of $82 \%$. The next section presents the aggregate data collected via survey and the gamified activity.

\subsection{Measures}

Student background variables. On the student information sheet, we asked questions about demographic information (e.g., gender $[$ Male $=1$; Female $=0]$ and age group), job status 
$($ No job $=1 ;$ Job $=0)$, student status (international student $=1$; domestic student $=0)$, average hours of study and work per week, and approach to learning. Two approaches to learning, i.e. surface approach and deep approach, were based on the 20-item 5-point scale $(1=$ never or only rarely true of me; 5 = always or almost always true of me), using the Study Process Questionnaire, developed by Biggs, Kember, and Leung (2001). Sample items include "I find most new topics interesting and often spend extra time trying to obtain more information about them" and "I find the best way to pass examinations is to try to remember answers to likely questions." Table 1 summarizes the demographic information, and Table 2 includes descriptive statistics for approach to learning. The sample was gender balanced. Slightly over $50 \%$ of participants had a job outside academic study. The majority of participants were younger than 24 years old.

Table 1

Demographic information $(n=136)$.

\begin{tabular}{|c|c|c|c|}
\hline Variable & Number (\%) & Variable & Number (\%) \\
\hline Gender & & \multicolumn{2}{|l|}{ Student status } \\
\hline Female & $70(51.5 \%)$ & Domestic student & $97(71.3 \%)$ \\
\hline Male & $66(48.5 \%)$ & International student & $39(28.7 \%)$ \\
\hline Job status & \multicolumn{3}{|c|}{ Hours of studying per week } \\
\hline Full-time job & $8(5.9 \%)$ & 1 to 10 hours & $17(12.6 \%)$ \\
\hline Part-time job & $66(48.5 \%)$ & 11 to 15 hours & $43(31.6 \%)$ \\
\hline \multirow[t]{5}{*}{ No job } & $62(45.6 \%)$ & 16 to 20 hours & $36(26.5 \%)$ \\
\hline & & 21 to 25 hours & $25(18.4 \%)$ \\
\hline & & 26 to 30 hours & $7(5.1 \%)$ \\
\hline & & More than 30 hours & $7(5.1 \%)$ \\
\hline & & Missing & $1(0.7 \%)$ \\
\hline Hours of work per week & & Age group & \\
\hline Don't have a job & $56(41.2 \%)$ & $19-24$ & $106(77.9 \%)$ \\
\hline Less than $10 \mathrm{hrs}$ & $14(10.3 \%)$ & $25-30$ & $19(14 \%)$ \\
\hline $11-15 \mathrm{hrs}$ & $26(19.1 \%)$ & $31-36$ & $6(4.4 \%)$ \\
\hline $16-30 \mathrm{hrs}$ & $28(20.6 \%)$ & $37-42$ & $2(1.5 \%)$ \\
\hline More than $30 \mathrm{hrs}$ & $10(7.4 \%)$ & Above 42 & $3(2.2 \%)$ \\
\hline Missing & $2(1.5 \%)$ & & \\
\hline
\end{tabular}

Participant engagement, attendance, and performance. There were a total of 51

online learning activities in two academic terms. Since Moodle generated reports about students' activity completion, data on student participation and completion 
(operationalization of behavioral engagement) in EL and SL were used to indicate "system use," as suggested in the information systems success model (Delone \& McLean, 2003). For each EL and SL, "1" was coded for an activity completion and "0" was coded for noncompletion. Therefore, the number of EL, SL, and Total completion (EL and SL) for each student could be calculated. Across two terms, the average completion rate of EL was $58 \%$ $(8.06 / 14)$ and that of SL was 26\% (9.51/37) (see Appendices A and B). Figure 3 shows the class attendance and EL completion rate by week. The average completion rate was $38 \%$ for 14 bronze-level SL activities, $18 \%$ for 14 silver-level SL activities, and $18 \%$ for 9 gold-level SL activities.

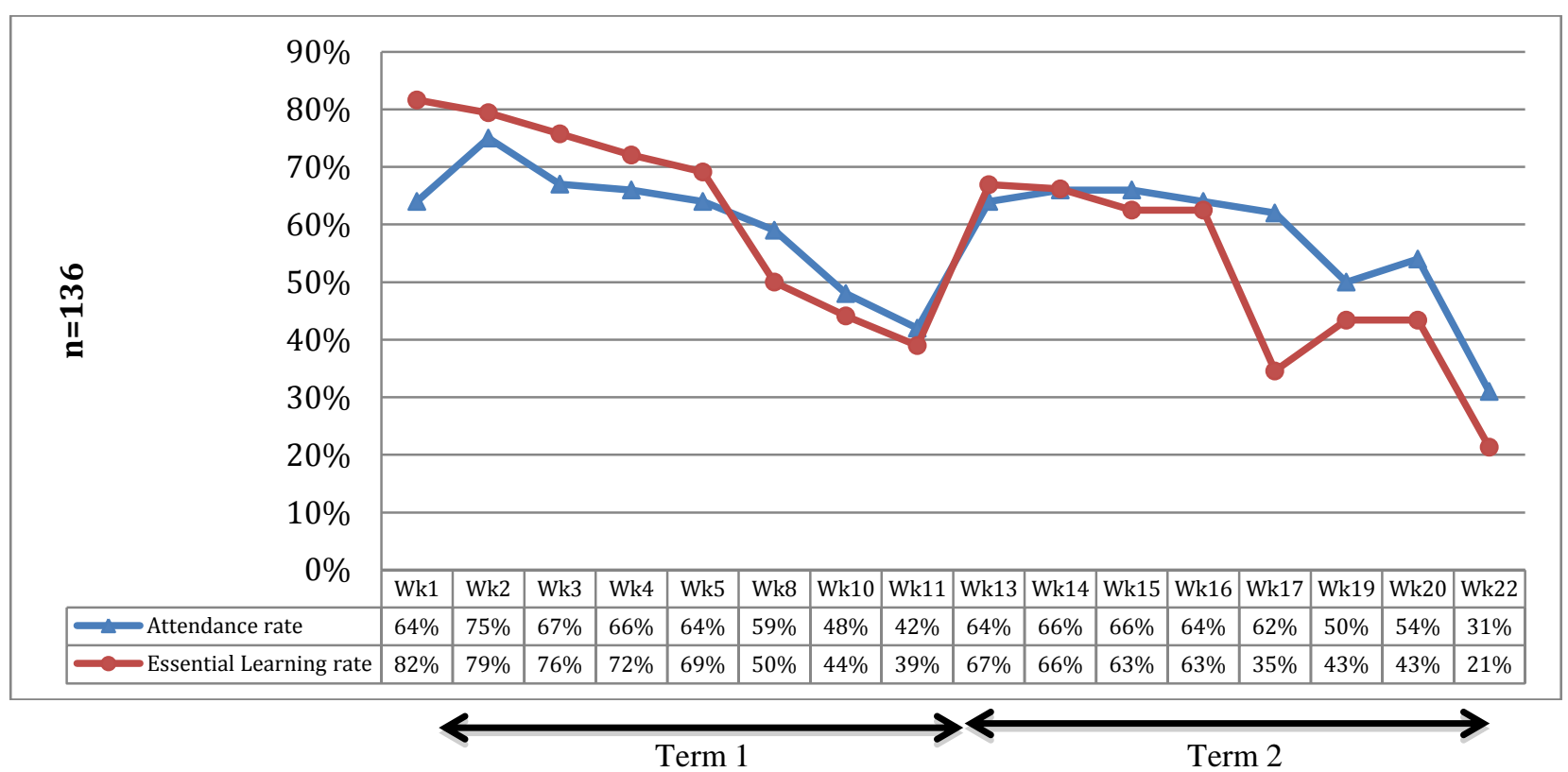

Fig. 3. Class attendance and Essential Learning completion rate $(n=136)$.

The course has three assessments: two portfolios consisting of essay tasks at the end of each term (Week 12 and Week 24) and engagement (Week 24). In addition, we obtained student performance in the Year 1 PPD course, as well as students' class attendance data from the university's portal. The record showed information on attendance for 23 weeks. Table 2 presents descriptive statistics for study approach, behavioral engagement, academic performance, and class attendance. Table 3 shows the correlation coefficients among the study variables. 
Table 2

Descriptive statistics for study approach, behavioral engagement, academic performance, and class attendance $(n=136)$.

\begin{tabular}{lccccc}
\hline Variable $(n=136)$ & Mean & Min & Max & Median & SD \\
\hline Approach to learning & & & & & \\
\hline Deep approach & 3.21 & 1.6 & 4.9 & 3.3 & 0.64 \\
Surface approach & 2.26 & 1.2 & 4.1 & 2.2 & 0.57 \\
\hline Behavioral engagement & & & & & \\
\hline No. of EL (14) & 8.06 & 0 & 14 & 8 & 4.34 \\
No. of SL (37) & 9.51 & 0 & 34 & 8 & 8.53 \\
No. of EL and SL (51) & 17.57 & 0 & 48 & 15 & 12.19 \\
No. of SL Bronze (14) & 5.37 & 0 & 14 & 5 & 2.08 \\
No. of SL Silver (14) & 2.52 & 0 & 12 & 2 & 2.67 \\
No. of SL Gold (9) & 1.63 & 0 & 9 & 1 & 4.3 \\
\hline Student performance & & & & & \\
\hline Portfolio 1 (35\%) & 62.06 & 0 & 82 & 64 & 14.91 \\
Portfolio 2 (55\%) & 59.95 & 0 & 85 & 63 & 17.57 \\
Engagement (10\%) & 67.38 & 20 & 95 & 70 & 18.01 \\
Total grade (100\%) & 61.35 & 0 & 83.05 & 64.4 & 15.01 \\
\hline Attendance & \multicolumn{5}{c}{} \\
\hline Class attendance & 13.54 & 2 & 21 & 14 & 4.20 \\
\hline
\end{tabular}


Table 3

Mean, standard deviation, and correlation among variables $(n=136)$.

\begin{tabular}{|c|c|c|c|c|c|c|c|c|c|c|c|c|c|c|c|}
\hline & Mean & S.D. & 1 & 2 & 3 & 4 & 5 & 6 & 7 & 8 & 9 & 10 & 11 & 12 & 13 \\
\hline 1. Gender & .49 & .50 & & & & & & & & & & & & & \\
\hline 3. Student status & .29 & .45 & .04 & -.06 & & & & & & & & & & & \\
\hline 5. Job hours & 1.42 & 1.40 & .12 & -.05 & -.11 & $-.88 * *$ & & & & & & & & & \\
\hline 6. Academic hours & 2.87 & 1.30 & .06 & -.01 & .07 & .03 & .002 & & & & & & & & \\
\hline 7. Deep approach & 3.18 & .69 & -.05 & .05 & -.10 & -.16 & $.18^{*}$ & $.30^{* *}$ & & & & & & & \\
\hline 10. Number of SL & 9.51 & 8.53 & -.14 & -.003 & .04 & $-.21^{*}$ & $.21 *$ & .14 & .16 & -.06 & $.77 * *$ & & & & \\
\hline 11. Number of EL $+S L$ & 17.57 & 12.19 & $-.22 *$ & .03 & .02 & $-.24 * *$ & $.23^{* *}$ & .14 & $.18^{*}$ & -.10 & $.90^{* *}$ & $.98^{* *}$ & & & \\
\hline 12. Class attendance & 13.54 & 4.20 & .04 & .001 & .08 & .000 & .02 & .11 & .02 & -.06 & $.28^{* *}$ & $.28^{* *}$ & $.30^{* * *}$ & & \\
\hline 13. PPD1 performance ${ }^{+}$ & 61.52 & 11.69 & -.01 & .055 & $-.22 *$ & -.06 & .13 & .05 & .13 & -.06 & $.31 * *$ & .19 & $.24 *$ & $.25^{* *}$ & \\
\hline 14. Course performance & 61.35 & 15.01 & -.16 & .07 & $-.18 *$ & $-.24 * *$ & $.21 *$ & .06 & $.23 * *$ & -.12 & $.34 * *$ & $28 * *$ & $.32 * *$ & $.39 * *$ & $.46^{* *}$ \\
\hline
\end{tabular}

EL indicates Essential Learning; SL, Super Learning; PPD, Personal and Professional Development. ${ }^{+} n=107$

$* p<0.05 ; * * p<0.01$. 


\subsection{Preliminary analyses}

SPSS version 21.0 (IBMCorp., 2012) was used for hypothesis testing and preliminary and posthoc data analyses. Several one-way analyses of variance (ANOVA) were performed to test the influence of nonhypothesized user background variables on class attendance, behavioral engagement outcomes, and academic performance. These background factors included student status (domestic versus international), age group, hours of study, and hours of work.

We used the Mann-Whitney U test for student status because of the unequal sample size in the two groups. Results showed no significant differences between domestic students and international students for attendance, behavioral engagement outcomes, and academic performance. We used the Kruskal-Wallis test for age group also because of unequal sample sizes among five age groups. Results revealed no significant differences among students in the five groups for attendance, behavioral engagement outcomes, and academic performance. Using a one-way ANOVA test for groups of average weekly academic hours indicated no significant differences in outcomes among groups.

Finally, use of the one-way ANOVA test for groups of average weekly job hours showed that students in different job hour groups did not differ on academic performance and class attendance; however, differences existed in behavior engagement in both EL and SL. Although post hoc analyses using the Scheffé post hoc criterion for significance did not show significant differences among groups, mean plots did graphically present differences in number of EL and SL tasks completed between the "1-10 hr" group and the "No job" group (mean difference $=8.911, p=0.178)$. 


\section{Results}

\subsection{Behavioral engagement and course performance}

Hypothesis 1 stated that students' engagement in the gamified course would be positively related to their course performance. Therefore, we used hierarchical multiple regression analysis to test the effect of EL and SL completion on academic performance, controlling for prior performance (i.e., PPD1 performance), gender, and class attendance. Because some students were direct entrants, we did not have their scores on PPD1; thus, a smaller sample size was used. As shown in Table 4, in Model 1, gender $(\beta=-0.17 ; p=$ $0.024)$, class attendance $(\beta=0.44 ; p<0.0001)$, and PPD1 performance $(\beta=0.35 ; p<0.0001)$ all significantly influenced course performance in year 2015-16. In Model 2, when the number of EL tasks completed was included as an additional independent variable, it also had a significant impact $(\beta=0.26 ; p=0.003)$ on course performance in $2015-16$. The change of $R^{2}$ from Model 1 to Model 2 was significant $(0.05 ; p=0.003)$. In Model 3, when the number of SL tasks completed was included as an additional independent variable, it also had a significant impact $(\beta=0.24 ; p=0.003)$ on course performance in 2015-16. The change of $R^{2}$ from Model 1 to Model 3 was significant $(0.05 ; p=0.002)$. Finally, in Model 4, the inclusion of the number of both EL and SL tasks completed added an additional significant influence on course performance $(\beta=0.27 ; p=0.001)$, also indicated by the significant $R^{2}$ change $(0.06 ; p=0.001)$. We concluded that hypothesis 1 was supported. 


\section{Table 4}

Summary of regression analysis for variables predicting academic performance in 2015-16 $(n=107)$

\begin{tabular}{lllll}
\hline Variable & Model 1 & Model 2 & Model 3 & Model 4 \\
\hline Step 1 & & & & \\
Gender & $-.17^{*}$ & -.08 & -.12 & -.10 \\
Class attendance & $.44^{* * *}$ & $.37^{* * *}$ & $.39^{* * *}$ & $.38^{* * *}$ \\
PPD1 performance & $.35^{* * *}$ & $.28^{* * *}$ & $.31^{* * *}$ & $.30^{* * *}$ \\
$\begin{array}{l}\text { Step 2 } \\
\text { Number of EL completion }\end{array}$ & & & & \\
Number of SL completion & & $.26^{* *}$ & & \\
Number of EL+SL completion & & & $.24^{* *}$ & \\
$F$ & $25.14^{* * *}$ & $22.78^{* * *}$ & $23.08^{* * *}$ & $.27^{* *}$ \\
$\begin{array}{l}\text { Adjusted } R^{2} \\
R^{2} \text { change }\end{array}$ & .406 & .451 & .455 & .460 \\
\hline
\end{tabular}

Note: Standardized coefficients are reported for tested variables.

$* p<0.05 ; * * p<0.01 ; * * * p<0.001$.

\subsection{Effectiveness of the gamified course}

Hypothesis 2 stated that student performance would be higher in the gamified condition than in the nongamified condition. To test this hypothesis, we compared the mean score difference on course performance between the gamified course in 2015-16 and the nongamified course in the previous year, i.e. 2014-15. Since the assessments in these 2 years consisted of almost identical portfolio tasks and assessment weights, we could compare the overall mean score difference. We found that students in the gamified course had a higher overall score $(M=62.69, S D=10.49)$ than students in the nongamified course $(M=58.67$, $\mathrm{SD}=10.96), \mathrm{t}(333)=-3.42, p=0.001$. Table 5 shows the difference of mean scores in the two courses based on specific assessments. In addition, we compared the mean score difference on course performance between students (the 2015-16 cohort) who participated in SL and those who did not participate. Table 6 shows a significant difference in course performance between these two groups; $\mathrm{t}(134)=-2.45, p=0.15$. We concluded that hypothesis 2 was supported. 
Table 5

Comparison of student performance between the gamified and the non-gamified course.

\begin{tabular}{lccccccc}
\hline Assessment (\%) & Cohort & $\mathbf{N}$ & Mean & SD & Df & $\boldsymbol{t}$ value & $\boldsymbol{p}$ value \\
\hline Portfolio 1 (35\%) & $14-15$ & 175 & 56.90 & 13.12 & 333 & -4.83 & .000 \\
& $15-16$ & 160 & 63.14 & 10.19 & & & \\
Portfolio 2 (55\%) & $14-15$ & 175 & 58.67 & 12.07 & 333 & -2.20 & .029 \\
& $15-16$ & 160 & 61.61 & 12.38 & & & \\
Engagement (10\%) & $14-15$ & 175 & 64.87 & 14.54 & 333 & -1.13 & .260 \\
& $15-16$ & 160 & 66.85 & 17.58 & & & \\
Final (100\%) & $14-15$ & 175 & 58.67 & 10.96 & 333 & -3.42 & .001 \\
& $15-16$ & 160 & 62.69 & 10.49 & & & \\
\hline
\end{tabular}

Table 6

Comparison of student performance between SL participants and nonparticipants.

\begin{tabular}{lccccccc}
\hline $\begin{array}{l}\text { Assessment } \\
(\%)\end{array}$ & SL & N & Mean & SD & Df & $\begin{array}{c}\boldsymbol{t} \\
\text { value }\end{array}$ & $\begin{array}{c}\boldsymbol{p} \\
\text { value }\end{array}$ \\
\hline Port folio 1 (35\%) & Participant & 117 & 62.96 & 14.17 & 134 & -1.78 & .081 \\
& Nonparticipant & 19 & 56.53 & 18.31 & & & \\
Portfolio 2 (55\%) & Participant & 117 & 61.07 & 18.03 & 134 & -1.86 & .065 \\
& Nonparticipant & 19 & 53.05 & 12.72 & & & \\
Engagement (10\%) & Participant & 117 & 70.78 & 15.97 & 133 & -6.106 & .000 \\
& Nonparticipant & 19 & 46.63 & 16.04 & & & \\
Final (100\%) & Participant & 117 & 62.61 & 15.10 & 134 & -2.464 & .015 \\
& Nonparticipant & 19 & 53.63 & 12.14 & & & \\
\hline
\end{tabular}

\subsection{Influence of student background variables}

Gender and behavioral engagement. Hypothesis 3 stated that female students would engage more in the gamified course than their male counterparts. After analysis, we found that there was a significant difference between male and female students in their behavioral engagement in $\operatorname{EL}\left(R^{2}=0.21, \mathrm{~F}(4,131)=8.46, \beta=-0.28, p<0.001\right)$ and total number of learning activities $\left(R^{2}=0.13, \mathrm{~F}(4,131)=4.90, \beta=-0.18, p=0.037\right)$, but not in SL $\left(R^{2}=0.09\right.$, $\mathrm{F}(4,131)=3.08, \beta=-0.11, p=0.22)($ see Table 7$)$. Therefore, Hypothesis 3 was partially supported.

Approach to learning and behavioral engagement. Hypothesis $4 \mathrm{a}$ stated that a deep study approach would be significantly related to behavioral engagement, while Hypothesis $4 \mathrm{~b}$ stated that a surface study approach would not be positively related to behavioral 
engagement. As indicated in Table 7, a surface approach did not have any significant relationship with $\mathrm{EL}(\beta=-0.11, p=0.16), \mathrm{SL}(\beta=-0.04, p=0.61)$ or total number of $\mathrm{EL}$ and SL $(\beta=-0.07, p=0.40)$. As to a deep approach, it did not have any significant relationship with $\operatorname{EL}(\beta=0.14, p=0.08)$, SL $(\beta=0.12, p=0.17)$, or total number of EL and $\operatorname{SL}(\beta=0.13, p=0.12)$. Hence Hypothesis $4 \mathrm{~b}$ was supported but Hypothesis $4 \mathrm{a}$ was not supported.

Job status and behavioral engagement. Hypothesis 5 stated that students with part time jobs would engage less in the gamified course. There were initially three groups for job status: full -time $(\mathrm{n}=8)$, part -time $(\mathrm{n}=66)$, and no job $(\mathrm{n}=62)$. We combined students with part- and full-time jobs, and therefore two groups representing job status $(0=$ student with job; 1 = student without job) were included in the regression analyses. As shown in Table 7 , student job status had significant relationships with number of EL completion $(\beta=-0.23, p=$ $0.004)$, number of SL completion $(\beta=-0.21, p=0.015)$, and total number of completion ( $\beta$ $=-0.23, p=0.007)$. Contrary to our hypothesis, students with a job participated in more online learning activities. Therefore, Hypothesis 5 was not supported.

Together, these student background variables explained 18\% of the variance in EL completion, $6 \%$ of the variance of SL completion, and $10 \%$ of the variance of EL and SL completion.

\section{Table 7}

Summary of regression analysis for user background variables predicting behavioral engagement $(n=$ 136).

\begin{tabular}{|c|c|c|c|c|c|c|c|c|c|}
\hline \multirow{2}{*}{$\begin{array}{l}\text { Dependent } \\
\text { variable }\end{array}$} & \multicolumn{3}{|c|}{ EL completion } & \multicolumn{3}{|c|}{ SL completion } & \multicolumn{3}{|c|}{ Total completion } \\
\hline & $B$ & $S E B$ & $\boldsymbol{\beta}$ & $B$ & $S E B$ & $\beta$ & $B$ & $S E B$ & $\boldsymbol{\beta}$ \\
\hline (Constant) & 9.32 & 2.21 & & 8.95 & 4.67 & & 18.26 & 6.51 & \\
\hline Gender & -2.46 & .69 & $-.28 * * *$ & -1.80 & 1.45 & -.11 & -4.25 & 2.01 & $-.18^{*}$ \\
\hline Surface approach & -.85 & .60 & -.11 & -.66 & 1.26 & -.04 & -1.50 & 1.76 & -.07 \\
\hline Deep approach & .87 & .50 & .14 & 1.43 & 1.04 & .12 & 2.30 & 1.46 & .13 \\
\hline Job status & -2.02 & .69 & $-.23 * *$ & -3.58 & 1.45 & $-.21 *$ & -5.60 & 2.03 & $-.23 * *$ \\
\hline$R^{2}$ & & .21 & & & .09 & & & .13 & \\
\hline$F$ & & $8.46 * * *$ & & & $3.08 *$ & & & $4.90 * *$ & \\
\hline Adjusted $R^{2}$ & & .18 & & & .06 & & & .10 & \\
\hline
\end{tabular}




\subsection{Posthoc analyses}

We conducted a number of posthoc analyses to examine the nonsignificant result of Hypothesis $4 \mathrm{a}$ and a few nonhypothesized relationships that may be useful to understand the effectiveness of a gamified course. Multiple regression analysis showed that none of the background variables were significantly related to class attendance. Moreover, student course performance did not differ by gender. Also, a surface approach did not influence course performance significantly. However, a deep learning approach $(\beta=0.18, p=0.03)$ and job status $(\beta=-0.22, p=0.009)$ were significantly related to course performance, as shown in Table 8 .

Table 8

Summary of regression analysis for user background variables, class attendance, and course performance $(n=136)$.

\begin{tabular}{lcccccc}
\hline & \multicolumn{3}{c}{ Course performance } & \multicolumn{3}{c}{ Class attendance } \\
\cline { 2 - 7 } Dependent variable & $B$ & $S E B$ & $\beta$ & $B$ & $S E B$ & $\beta$ \\
\hline (Constant) & 59.11 & & & 14.44 & & \\
Gender & -3.2 & 2.48 & -.11 & .50 & .74 & .06 \\
Surface approach & -2.56 & 2.17 & -.10 & -.48 & .65 & -.74 \\
Deep approach & 3.96 & 1.80 & $.18^{*}$ & .05 & .54 & .09 \\
Job status & -6.61 & 2.50 & $-.22^{* *}$ & -.45 & .75 & -.61 \\
$R^{2}$ & & .13 & & & .10 & \\
$F$ & & $4.75^{* *}$ & & & .30 & \\
Adjusted $R^{2}$ & & .10 & & & -.02 & \\
\hline
\end{tabular}

\section{Discussion}

\subsection{Benefits of educational gamification}

Many people believe that nontraditional teaching methods through technologymediated learning can improve student engagement. This view was confirmed by a metaanalysis on the impact of online learning methods on education commissioned by the U.S. Department of Education (Means, Toyama, Murphy, Bakia, \& Jones, 2009), where the authors found that both online and hybrid courses have a positive impact on learning outcomes, with hybrid courses having a greater impact. However, the "positive effects associated with blended learning should not be attributed to the media, per se" (p. ix). Indeed, 
inappropriate use of VLEs may lead to student boredom, lack of interest, monotony, and lack of motivation, causing students to engage less in the VLE (Chen, Lambert, \& Guidry, 2010). A key to meaningful engagement is embedding motivational properties in the technologymediated learning environment.

A gamified course allows motivational affordance through the implementation of game elements (Antin, 2012; Deterding, Dixon, Khaled, \& Nacke, 2011; Landers \& Callan, 2011), so that student behavioral engagement may be more evident. In our case, the design of EL showed progression of learning and gave quick feedback. Further, badges awarded for EL completion and leaderboard acknowledged student achievement. Our gamified course also enabled flipped classroom and student-centered learning activities. First, a flipped classroom could be implemented so that students learn content knowledge online outside the classroom and then participate in seminar exercises by applying content knowledge. Second, based on course feedback, students expressed that they had more interactions with peer learners for problem solving and brainstorming in seminar exercises. As a result, the student-centered learning environment was enhanced (Hannafin \& Land, 1997).

Another potential benefit of the approach is that it can help address learning needs of a diverse class. For example, many students in the course have part -time jobs. Though their class attendance was not significantly different from that of students with no jobs, they did engage more in online learning. It seems that the self-paced, freedom-of-choice nature of SL allows students to learn in a more flexible and autonomous way. Furthermore, it is believed that SL, as optional learning activities with different levels of difficulty, can provide challenges to high -ability learners. More choice and control over learning, a higher level of challenge and complexity, and caring teachers help high -ability learners overcome any boredom in the learning process (Scager, Akkerman, Pilot, \& Wubbels, 2014).

\subsection{Caveats}


While positive results from testing the first two hypotheses offer convincing evidence of the value of gamification to engage students in learning, some research cautions against excessive focus on the achievement aspect of gamification (e.g., visible status and virtual collections), since learning based on extrinsic rewards is unsustainable in the long run. Deci, Koestner, and Ryan (2001) demonstrated that all forms of rewards (extrinsic motivation) eventually erode intrinsic motivation. This view was supported by the decline of student engagement in our design, especially towards the end of the two-academic-term teaching period. Therefore, designing learning activities in a meaningful way that intrinsically motivates students becomes key for "meaningful gamification" (Nicholson, 2015). Echoing the idea of student-centered learning environments, researchers have suggested that meaningful gamification can be achieved by inviting users to design their learning goals and assessments. For example, (Kofinas, 2016) proposed a narrative approach to assessment. He suggested that gamification can help educators develop narratives where both formative and summative assessments of the assessment regime can be incorporated as challenges to be overcome. Inviting students to set up challenges for themselves by developing formative assessments that help with their goal setting can lead to more engaged students who put in extra effort to achieve the learning goals they set.

Users can also be invited to give feedback at different stages of system development (Gulliksen et al., 2003). It is acknowledged that there are multiple indicators of the success of a gamified system. Particularly, the information systems success model (Delone \& McLean, 2003) maintains that system quality, information quality, service quality, system use, and user satisfaction are all relevant to the success of an information system. Therefore, we believe that the aforementioned aspects are all worthy of being examined in future research for the effectiveness and/or ineffectiveness of an IT-based gamified course. 
Furthermore, there is a paucity of testing of the effectiveness of educational gamification in students' whole academic life, and our current understanding of educational gamification is not focused on intrinsic and sustainable learning. It is recommended that gamified system designers think about ways to motivate users using engagement and progression loops (motivation $\rightarrow$ action $\rightarrow$ feedback $\rightarrow$ motivation) in the long run. As suggested by (Werbach \& Hunter, 2012), in the planning/design stage of a gamified course, designers need to understand and map out the kinds of feedback the gamified system will offer to the players to encourage further action, and they need to explain how players (both new and more experienced) will progress and engage in the system. A concept related to creating an engagement loop to constantly motivate users is called "novelty effect," proposed by Hamari et al. (2014) and discussed in other studies (de-Marcos, Garcia-Lopez, \& GarciaCabot, 2016; Hamari \& Koivisto, 2015; Hanus \& Fox, 2015). The novelty phenomenon of gamification purports that gamification is able to change user behavior because users are curious about gamification and want to try it out. However, when the novelty wears off, the changed behavior levels may decrease.

Our two-academic-term, longitudinal study suggested that novelty effect seems to influence student engagement, as reflected in the EL completion rate decline as the terms progressed (see Figure 1). However, the rise of EL completion at the beginning of the second term suggests that the novelty effect did not completely wipe out students' interest in the gamified course. Another issue that may have impacted student engagement is the summative assessments. Before the deadline for each summative assessment, we witnessed a drop in attendance with a slight pick up immediately after the submission of the first portfolio. Interestingly, there is evidence, such as a 2-year longitudinal study by Hamari (2015), that suggests there are positive long-term effects in using gamified approaches in education, as users in the gamified condition are significantly more likely to post trade proposals, carry out 
transactions, comment on proposals, and generally use the service in an active way (Hamari, 2015). As a result, a longitudinal study of student experience with gamified courses in a degree program could be an important avenue for future study.

\subsection{Understanding users for a better course design}

Hamari et al. (2014) mentioned that the nature of the system (e.g., hedonic or utilitarian), user qualities, and the social environment influence the effectiveness of gamification. The latter two highlight the importance of understanding student users in a gamified course. Nicholson (2012) suggested that designers should involve the users in the customization of the gamified system and the development of meaningful game elements and goals that are in line with their own interests. In the educational context, the student-centered framework is especially important to address learning needs and the engagement of a diverse class (Tomlinson, 2014). In this exploratory study, we examined a few user background variables, trying to understand how these factors influence student engagement in the gamified course.

First, female students engaged in more EL than their male counterparts and, in general, engaged in more learning activities. However, there was not a significant gender difference in engagement in SL, course performance, and class attendance (see 4.4 posthoc analyses). It is interesting to see differential gender behavior in online learning. Our results may be explained by the findings of Koivisto and Hamari (2014) and Venkatesh et al. (2000), who showed that women perceived greater social and hedonic benefits from the use of gamification, while men may engage more in a gamified system due to utilitarian benefits. A pedagogical implication is that the design of learning activities should provide benefits that are perceived as valuable by students of both genders.

Second, we did not find significant relationships between learning approaches and behavioral engagement. Although approach to learning does not shed light on how to engage 
users in the gamified course, this motivational factor still influences the effectiveness of the gamified course in terms of user performance. As indicated by the post hoc analyses, a deep approach was significantly related to course performance, while a surface approach was not; however, neither approach seemed significantly linked to the gamified intervention. For educators whose primary goals are to enhance deep learning and academic performance, an insight would be carefully consider assessment strategies, conceptions of teaching, and choices that can be given to students (Baeten, Kyndt, Struyven, \& Dochy, 2010).

The most surprising finding relates to Hypothesis 5, the impact that students' job status had on their engagement in the gamified course. Contrary to our hypothesis, students with a job (whether part -time or full -time) engaged more with EL and SL than students without a job. Posthoc analyses showed no significant difference in class attendance between the two groups. One explanation for this unexpected finding can be drawn from the human resource management literature on flexible work arrangements, which can provide individuals with perceived flexibility, resulting in higher engagement (Richman, Civian, Shannon, Jeffrey Hill, \& Brennan, 2008). This links to an observation by Wood and Reiner (2012) that the fixed structure of higher education learning practice may be a limitation forced by tradition, which limits students and their performance by fitting them into a nonindividualized structure. We believe that VLE-based activities allowed students to complete many of their assessment activities with greater time flexibility. We can reasonably infer that the online learning activities in the gamified course provided benefits of perceived flexibility and autonomy of learning to students who occupied multiple roles in life (worker as well as student), leading to higher engagement and performance in learning.

Despite its merits, a major limitation of this study was that we examined only a limited number of student background variables. The literature in higher education and gamification suggests that other variables may be equally important, such as personality (Codish \& Ravid, 
2014), gamer type (Hamari, Koivisto, \& Sarsa, 2014; Hamari \& Tuunanen, 2014), and attitudes toward game-based learning and experience with games (Landers \& Armstrong, 2015). Our results suggest that a gamified course may not be equally effective for all students. We mentioned its potential advantages for students with jobs and high -ability students. However, anecdotal evidence from students in the course suggests that mature students did not perceive the usefulness of a gamified course and therefore did not spend much time with the online learning activities. In addition, future studies could examine the learning experience and outcomes of students at different levels of educational achievement. Overall, to improve the quality of the gamified course, it will be useful to invite students with different backgrounds to experience the system and provide feedback on their experience with it at each stage of the design process.

\section{Conclusion}

We designed a gamified course using a wide variety of game mechanics to engage students in learning and satisfy the needs of a diverse class. The course design based on gamification was found to contribute to student-centered learning and enable the use of a flipped classroom. The effectiveness of the gamified course was positive in terms of a high level of student behavioral engagement in online learning and improved course performance compared to the nongamified condition. The gamified course, potentially, can serve the learning needs of a diverse class and challenge high -ability students, and it was particularly beneficial to learners who were working part-time and female students. The results indicate that technology-mediated gamified systems may provide additional benefits if they fit the lifestyle of the students (working students) and the motivations of the students (social relatedness for female students). 


\section{References}

Ahuja, M. K., \& Thatcher, J. B. (2005). Moving beyond intentions and toward the theory of trying: effects of work environment and gender on post-adoption information technology use. MIS quarterly, 29(3), 427-459.

Anderson, A., Huttenlocher, D., Kleinberg, J., \& Leskovec, J. (2014). Engaging with massive online courses. Paper presented at the Proceedings of the 23rd international conference on World wide web.

Anderson, L. W., Krathwohl, D. R., \& Bloom, B. S. (2001). A taxonomy for learning, teaching, and assessing: A revision of Bloom's taxonomy of educational objectives: Allyn \& Bacon.

Antin, J. (2012). Gamification: Designing for Motivation. Interactions, 14.

Baard, P. P., Deci, E. L., \& Ryan, R. M. (2004). Intrinsic need satisfaction: A motivational basis of performance and well Being in two work settings. Journal of Applied Social Psychology, 34(10), 2045-2068.

Baeten, M., Kyndt, E., Struyven, K., \& Dochy, F. (2010). Using student-centred learning environments to stimulate deep approaches to learning: Factors encouraging or discouraging their effectiveness. Educational Research Review, 5(3), 243-260.

Banfield, J., \& Wilkerson, B. (2014). Increasing student intrinsic motivation and self-efficacy through gamification pedagogy. Contemporary Issues in Education Research (Online), 7(4), 291-298.

Barata, G., Gama, S., Jorge, J., \& Gonçalves, D. (2013). Improving participation and learning with gamification. Paper presented at the Proceedings of the First International Conference on gameful design, research, and applications. 
Biggs, J., Kember, D., \& Leung, D. Y. P. (2001). The revised two-factor study process questionnaire: R-SPQ-2F. British Journal of Educational Psychology, 71(1), 133-149.

Blohm, I., \& Leimeister, J. M. (2013). Gamification: Design of IT-based enhancing services for motivational support and behavioral change. Business \& Information Systems Engineering 5(4), 275-278.

Bostrom, R. P., \& Heinen, J. S. (1977). MIS problems and failures: A socio-technical perspective, Part II: The application of socio-technical theory. MIS quarterly, 11-28.

Caton, H., \& Greenhill, D. (2013). The effects of gamification on student attendance and team performance in a third-year undergraduate game production module. Paper presented at the European Conference on Games Based Learning.

Chen, P.-S. D., Lambert, A. D., \& Guidry, K. R. (2010). Engaging online learners: The impact of Web-based learning technology on college student engagement. Computers \& Education, 54(4), 1222-1232.

Codish, D., \& Ravid, G. (2014). Personality based gamification-Educational gamification for extroverts and introverts. Paper presented at the Proc. 9 th Chais Conf. for the Study of Innovation and Learning Technologies: Learning in the Technological Era.

Cruz, L., \& Penley, J. (2014). Too cool for school? The effects of gamification in an advanced interdisciplinary course. Journal of Teaching and Learning with Technology, 3(2), 1-11.

de-Marcos, L., Garcia-Lopez, E., \& Garcia-Cabot, A. (2016). On the effectiveness of gamelike and social approaches in learning: Comparing educational gaming, gamification \& social networking. Computers \& Education, 95, 99-113.

de Sousa Borges, S., Durelli, V. H., Reis, H. M., \& Isotani, S. (2014). A systematic mapping on gamification applied to education. Paper presented at the Proceedings of the 29th Annual ACM Symposium on Applied Computing. 
Deci, E. L., Koestner, R., \& Ryan, R. M. (2001). Extrinsic rewards and intrinsic motivation in education: Reconsidered once again. Review of Educational Research, 71(1), 1-27.

Deci, E. L., \& Ryan, R. M. (2002). Handbook of self-determination research: University Rochester Press.

Delone, W. H., \& McLean, E. R. (2003). The DeLone and McLean model of information systems success: A ten-year update. Journal of management information systems, 19(4), 9-30.

Denny, P. (2013). The effect of virtual achievements on student engagement. Paper presented at the Proceedings of the SIGCHI conference on human factors in computing systems.

Deterding, S., Dixon, D., Khaled, R., \& Nacke, L. (2011). From game design elements to gamefulness: defining gamification. Paper presented at the Proceedings of the 15th international academic MindTrek conference: Envisioning future media environments.

Dicheva, D., Dichev, C., Agre, G., \& Angelova, G. (2015). Gamification in education: A systematic mapping study. Educational Technology \& Society, 18(3), 1-14.

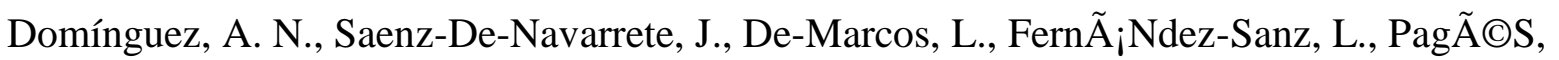
C., \& MartÃNez-HerrÃ $; I z$, J.-J. (2013). Gamifying learning experiences: Practical implications and outcomes. Computers \& Education, 63, 380-392.

Gåsland, M. (2011). Game mechanic based e-learning. Science And Technology, Master Thesis (June 2011). Available at: http://ntnu. diva-portal. org/smash/get/diva2, 441760.

Gibbs, G. (2014). Student engagement, the latest buzzword. Times Higher Education.

Gilboy, M. B., Heinerichs, S., \& Pazzaglia, G. (2015). Enhancing student engagement using the flipped classroom. Journal of Nutrition Education and Behavior, 47(1), 109-114. 
Greenhaus, J. H., \& Beutell, N. J. (1985). Sources of conflict between work and family roles. Academy of Management Review, 10(1), 76-88.

Gulliksen, J., Göransson, B., Boivie, I., Blomkvist, S., Persson, J., \& Cajander, Å. (2003). Key principles for user-centred systems design. Behaviour and Information Technology, 22(6), 397-409.

Hall, R. (2010). The work-study relationship: experiences of full-time university students undertaking part-time employment. Journal of Education and Work, 23(5), 439-449.

Hamari, J. (2015). Do badges increase user activity? A field experiment on the effects of gamification. Computers in human behavior, 1-10.

Hamari, J., \& Koivisto, J. (2015). Why do people use gamification services? International Journal of Information Management, 35(4), 419-431.

Hamari, J., Koivisto, J., \& Sarsa, H. (2014). Does gamification work?--a literature review of empirical studies on gamification. Paper presented at the 2014 47th Hawaii International Conference on System Sciences.

Hamari, J., \& Tuunanen, J. (2014). Player types: A meta-synthesis. Transactions of the Digital Games Research Association, 1(2), 29-53.

Hannafin, M. J., \& Land, S. M. (1997). The foundations and assumptions of technologyenhanced student-centered learning environments. Instructional Science, 25(3), 167202.

Hanus, M. D., \& Fox, J. (2015). Assessing the effects of gamification in the classroom: A longitudinal study on intrinsic motivation, social comparison, satisfaction, effort, and academic performance. Computers \& Education, 80, 152-161.

Hepplestone, S., Holden, G., Irwin, B., Parkin, H. J., \& Thorpe, L. (2011). Using technology to encourage student engagement with feedback: a literature review. Research in Learning Technology, 19(2), 117-127. 
Huotari, K., \& Hamari, J. (2012). Defining gamification: a service marketing perspective. Paper presented at the Proceeding of the 16th International Academic MindTrek Conference.

IBMCorp., I. (2012). IBM SPSS Statistics for Windows, Version 21.0: IBM Corp Armonk, NY.

Iosup, A., \& Epema, D. (2014). An experience report on using gamification in technical higher education. Paper presented at the Proceedings of the 45th ACM technical symposium on Computer science education.

Kember, D., Charlesworth, M., Davies, H., McKay, J., \& Stott, V. (1997). Evaluating the effectiveness of educational innovations: Using the Study Process Questionnaire to show that meaningful learning occurs. Studies in Educational Evaluation, 23(2), 141157.

Kofinas, A. (2016). In favour of a gamified, narrative-based assessment regime [Electronic Version]. Chartered Association of Business Schools from https://charteredabs.org/infavour-of-a-gamified-narrative-based-assessment-regime/

Koivisto, J., \& Hamari, J. (2014). Demographic differences in perceived benefits from gamification. Computers in Human Behavior, 35, 179-188.

Landers, R. N., \& Armstrong, M. B. (2015). Enhancing instructional outcomes with gamification: An empirical test of the Technology-Enhanced Training Effectiveness Model. Computers in Human Behavior, 1-9.

Landers, R. N., \& Callan, R. C. (2011). Casual social games as serious games: The psychology of gamification in undergraduate education and employee training. In Serious games and edutainment applications (pp. 399-423): Springer. 
Lea, S. J., Stephenson, D., \& Troy, J. (2003). Higher education students' attitudes to studentcentred learning: beyond 'educational bulimia'? Studies in higher education, 28(3), 321-334.

Lim, D. H., \& Kim, H. (2003). Motivation and learner characteristics affecting online learning and learning application. Journal of Educational Technology Systems, 31(4), 423-439.

Lonka, K., \& Ahola, K. (1995). Activating instruction: How to foster study and thinking skills in higher education. European Journal of Psychology of Education, 10(4), 351368.

McLaughlin, J. E., Roth, M. T., Glatt, D. M., Gharkholonarehe, N., Davidson, C. A., Griffin, L. M., et al. (2014). The flipped classroom: a course redesign to foster learning and engagement in a health professions school. Academic Medicine, 89(2), 236-243.

Means, B., Toyama, Y., Murphy, R., Bakia, M., \& Jones, K. (2009). Evaluation of evidencebased practices in online learning: A meta-analysis and review of online learning studies. US Department of Education.

Nicholson, S. (2012). A user-centered theoretical framework for meaningful gamification. Games+ Learning + Society, 8(1), 223-230.

Nicholson, S. (2015). A recipe for meaningful gamification. In Gamification in education and business (pp. 1-20): Springer.

Norman, D. A. (1990). The Psychology of Everyday Actions. The Design of Everyday Things. New York: Doubleday/Currency.

Price, L., \& Kirkwood, A. (2011). Enhancing professional learning and teaching through technology: a synthesis of evidence-based practice among teachers in higher education. York, UK: High Education Academy. 
Richman, A. L., Civian, J. T., Shannon, L. L., Jeffrey Hill, E., \& Brennan, R. T. (2008). The relationship of perceived flexibility, supportive workâ€"life policies, and use of formal flexible arrangements and occasional flexibility to employee engagement and expected retention. Community, work and family, 11(2), 183-197.

Richmond, L. (2013). Student part-time work increases. Times Higher Education, 2.

Ryan, R. M., \& Deci, E. L. (2000). Self-determination theory and the facilitation of intrinsic motivation, social development, and well-being. American Psychologist, 55(1), 68-78.

Scager, K., Akkerman, S. F., Pilot, A., \& Wubbels, T. (2014). Challenging high-ability students. Studies in Higher Education, 39(4), 659-679.

Seaborn, K., \& Fels, D. I. (2015). Gamification in theory and action: A survey. International Journal of Human-Computer Studies, 74, 14-31.

Slavin, R. E. (1987). A theory of school and classroom organization. Educational Psychologist, 22(2), 89-108.

Tomlinson, C. A. (2014). Differentiated classroom: Responding to the needs of all learners. Alexandria, VA, USA: Ascd.

Venkatesh, V., Morris, M. G., \& Ackerman, P. L. (2000). A longitudinal field investigation of gender differences in individual technology adoption decision-making processes. Organizational Behavior and Human Decision Processes, 83(1), 33-60.

Werbach, K., \& Hunter, D. (2012). For the win: How game thinking can revolutionize your business: Wharton Digital Press.

Williams, D., Consalvo, M., Caplan, S., \& Yee, N. (2009). Looking for gender: Gender roles and behaviors among online gamers. Journal of Communication, 59(4), 700-725.

Wood, L. C., \& Reiners, T. (2012). Gamification in logistics and supply chain education: Extending active learning. Paper presented at the IADIS International Conference on Internet Technologies \& Society, Perth, Australia. 
Yorke, M., \& Knight, P. (2006). Embedding employability into the curriculum (Vol. 3). York, UK: Higher Education Academy

Zichermann, G., \& Cunningham, C. (2011). Gamification by design: Implementing game mechanics in web and mobile apps: " O'Reilly Media, Inc." 


\section{Appendix A}

Student participation in Essential Learning $(n=166)$

\begin{tabular}{clccc}
\hline Week of & & Activity & \multicolumn{2}{c}{ Completion } \\
\cline { 3 - 5 } activity & Title of activity & code & $\mathrm{N}$ & $\%$ \\
\hline 1 & Student information sheet & $\mathrm{A} 1$ & 111 & $67 \%$ \\
2 & What is it that you like about your job? & $\mathrm{A} 4$ & 108 & $65 \%$ \\
3 & What do employers want? & $\mathrm{A} 7$ & 103 & $62 \%$ \\
4 & Critical thinking part 1 & $\mathrm{A} 12$ & 98 & $59 \%$ \\
5 & Critical thinking part 2 & $\mathrm{A} 15$ & 94 & $57 \%$ \\
8 & Email etiquette & $\mathrm{A} 23$ & 68 & $41 \%$ \\
10 & Are you using the right medium for the message? & $\mathrm{A} 29$ & 60 & $36 \%$ \\
11 & Your personal brand. What does your online profile & $\mathrm{A} 33$ & 53 & $32 \%$ \\
& say about you? & & & \\
13 & Introduction to management research & $\mathrm{A} 35$ & 91 & $55 \%$ \\
14 & Introduction to questionnaire design & $\mathrm{A} 36$ & 90 & $54 \%$ \\
$15-16$ & Literature review & $\mathrm{A} 38$ & 85 & $51 \%$ \\
17 & Video lectures on methodology & $\mathrm{A} 43$ & 47 & $28 \%$ \\
$19-20$ & Interpreting \& presenting data & $\mathrm{A} 45$ & 59 & $36 \%$ \\
24 & Course satisfaction survey & $\mathrm{A} 52$ & 29 & $17 \%$ \\
\hline Average & & & $\mathbf{7 8 . 2 8}$ & $\mathbf{5 8 \%}$ \\
\hline
\end{tabular}




\section{Appendix B}

Student participation in Super Learning $(n=166)$

\begin{tabular}{|c|c|c|c|c|c|}
\hline \multirow{2}{*}{$\begin{array}{l}\text { Week of } \\
\text { activity }\end{array}$} & \multirow[b]{2}{*}{ Title of activity } & \multirow{2}{*}{$\begin{array}{l}\text { Activity } \\
\text { code }\end{array}$} & \multirow{2}{*}{$\begin{array}{c}\text { Type of } \\
\text { task }\end{array}$} & \multicolumn{2}{|c|}{ Completions } \\
\hline & & & & $\mathrm{N}$ & $\%$ \\
\hline 2 & What am I like? & $\mathrm{A} 2$ & Bronze & 92 & $55 \%$ \\
\hline 2 & What am I like (suggested questions) & A3 & Bronze & 55 & $33 \%$ \\
\hline 3 & What job(s) am I interested in? & A5 & Silver & 20 & $12 \%$ \\
\hline 3 & Recommended videos & A6 & Bronze & 79 & $48 \%$ \\
\hline 4 & Feedback on Week 4: Transferable skills & $\mathrm{A} 8^{*}$ & Silver & 25 & $15 \%$ \\
\hline 4 & Evidence-based learning & A9* & Bronze & 12 & $7 \%$ \\
\hline 4 & Additional resources & $\mathrm{A} 10$ & Bronze & 75 & $45 \%$ \\
\hline 4 & Edit your user profile and earn a Gold badge! & $\mathrm{A} 11 *$ & Gold & 16 & $10 \%$ \\
\hline 5 & $\begin{array}{l}\text { Types of arguments and how to make arguments } \\
\text { stronger }\end{array}$ & A13 & Bronze & 69 & $42 \%$ \\
\hline 5 & Feedback on Week 5: Critical thinking 1 & A14* & Silver & 22 & $13 \%$ \\
\hline 6 & Quiz on recognizing false premises & A16 & Silver & 66 & $40 \%$ \\
\hline 6 & Quiz on identifying underlying assumptions & A17 & Gold & 63 & $38 \%$ \\
\hline 6 & Additional slides on underlying assumptions & A18 & Bronze & 43 & $26 \%$ \\
\hline 6 & Evaluating your own written arguments & A19 & Gold & 6 & $4 \%$ \\
\hline 7 & Watch the BSEO placement video & A20 & Bronze & 69 & $42 \%$ \\
\hline 8 & Evidence-based learning & A $21 *$ & Silver & 28 & $17 \%$ \\
\hline 8 & High flier research: The graduate market in 2015 & A22 & Bronze & 19 & $11 \%$ \\
\hline 9 & Email correspondence guide & A24 & Silver & 12 & $7 \%$ \\
\hline 9 & Feedback on Week 9: Email etiquette & A25 & Silver & 0 & $0 \%$ \\
\hline 10 & Feedback on Week 10: Thinking like a manager & A26* & Silver & 13 & $8 \%$ \\
\hline 10 & Video lectures on persuasive writing and feedback & $\mathrm{A} 27, \mathrm{~A} 28$ & Gold & & $0 \%$ \\
\hline 11 & Recommended articles and videos & $\mathrm{A} 30$ & Bronze & 23 & $14 \%$ \\
\hline 11 & $\begin{array}{l}\text { Feedback on Week 11: Are you using the right } \\
\text { medium for the message? }\end{array}$ & $\mathrm{A} 31^{*}$ & Silver & 38 & $23 \%$ \\
\hline 12 & Comparing CVs & $\mathrm{A} 32$ & Gold & 8 & $5 \%$ \\
\hline 12 & Tips for an engaging LinkedIn profile in your sector & A34 & Gold & 39 & $23 \%$ \\
\hline 14 & More tips on formulating your research question & A37 & Silver & 36 & $22 \%$ \\
\hline 15 & Slides of evaluative and constructive critique & A39 & Bronze & 71 & $43 \%$ \\
\hline 15 & $\begin{array}{l}\text { Have you finished reading the excerpt of } \\
\text { "determinants of performance among shop floor } \\
\text { employees?" }\end{array}$ & $\mathrm{A} 40^{*}$ & Silver & 55 & $33 \%$ \\
\hline 16 & Evidence-based learning & A41 & Gold & 11 & $7 \%$ \\
\hline 16 & Additional video & A42 & Bronze & 16 & $10 \%$ \\
\hline 17 & Feedback on Week 22: Methodology & A $44 *$ & Silver & 50 & $30 \%$ \\
\hline 19 & $\begin{array}{l}\text { Feedback on Week 24: Interpreting and presenting } \\
\text { data }\end{array}$ & A $46^{*}$ & Silver & 38 & $23 \%$ \\
\hline 20 & Evidence-based learning & A47 & Gold & 10 & $6 \%$ \\
\hline 20 & Additional slides & A48 & Bronze & 11 & $7 \%$ \\
\hline 21 & Additional slides on writing up the research report & A49 & Bronze & 33 & $20 \%$ \\
\hline 22 & Feedback on group Vivas & A50* & Gold & 41 & $25 \%$ \\
\hline 24 & Preparing for your dissertation & A51 & Silver & 11 & $7 \%$ \\
\hline Average & & & & 34.97 & $26 \%$ \\
\hline
\end{tabular}

*Activity with a completion deadline. 
Enhancing student learning experience with technology-mediated gamification: An empirical study

\section{Highlights}

- An IT-based gamified course was developed to support student-centered learning.

- Course performance was significantly better in the gamified condition than in the nongamified one.

- Engagement in online learning activities was positively related to course performance.

- Female students and students with jobs engaged significantly more in online learning activities. 